\title{
BMJ Open Suicidal ideation in relation to disordered eating, body size and weight perception: a cross-sectional study of a Norwegian adolescent population: the HUNT Study
}

\author{
Farzaneh Saeedzadeh Sardahaee, ${ }^{\odot 1,2}$ Turid Lingaas Holmen, ${ }^{3}$ Nadia Micali, ${ }^{4,5}$ \\ Erik R Sund, ${ }^{6}$ Ottar Bjerkeset, ${ }^{7,8}$ Kirsti Kvaløy ${ }^{9,10}$
}

To cite: Saeedzadeh

Sardahaee F, Holmen TL, Micali N, et al. Suicidal ideation in relation to disordered eating, body size and weight perception: a cross-sectional study of a Norwegian adolescent population: the HUNT Study. BMJ Open 2019;9:e029809. doi:10.1136/ bmjopen-2019-029809

- Prepublication history and additional material for this paper are available online. To view these files, please visit the journal online (http://dx. doi org/10.1136/bmjopen-2019029809).

Received 6 March 2019 Revised 23 June 2019 Accepted 28 June 2019
Check for updates

(C) Author(s) (or their employer(s)) 2019. Re-use permitted under CC BY-NC. No commercial re-use. See rights and permissions. Published by BMJ.

For numbered affiliations see end of article.

\section{Correspondence to} Dr Farzaneh Saeedzadeh Sardahaee;

farzaneh.sardahaee@ googlemail.com

\section{ABSTRACT}

Objective We conducted a population-based study on a sample of more than 7000 adolescents where we examined the associations between suicidal ideation (SI) and disordered eating (DE) and its related traits.

Design Cross-sectional.

Settings Data were derived from two Norwegian population-based cohorts, the Young-HUNT1 (1995-1997) and Young-HUNT3 (2006-2008) from the county of NordTrøndelag, Norway.

Participants A total of 7268 adolescents (15-19 years) who had completed self-reported questionnaires including items on SI, DE, body size and weight perception were included.

Primary outcome measures ORs for SI given DE, body size or weight perception. Analyses were performed in multivariate logistic regression models.

Results The prevalence of SI was $23.1 \%$ in total population. Both girls and boys who reported DE, evaluated their body size as not 'about the same as others' or were 'unhappy about their weight' had between twofold to fivefold increase in odds for Sl; these incremental risks were observed independent of sex, age, body mass index and socioeconomic status. We observed higher odds for SI among boys.

Conclusions Our findings suggest a clear association between SI and DE and its associated traits, in both genders but especially in males. Special attention should be paid on early detection of $D E$ traits among adolescents.

\section{INTRODUCTION}

Suicide presides above all other causes of death in individuals aged $15-39$ years. ${ }^{1}$ The WHO has urged countries to invest in comprehensive suicide prevention strategies ${ }^{2}$ that identify and address the factors underlying suicidal ideation (SI), suicidal attempt and suicide. SI varies in form and degree of severity, from fleeting thoughts to detailed planning. A meta-analysis of 172 longitudinal studies ${ }^{3}$ has shown that in adults, SI

\section{Strengths and limitations of this study}

- We have identified detectable yet somewhat overlooked factors that may assist in addressing suicidal ideation (SI) in adolescents.

- Our results are of general relevance since our observations were made in a large, population-based adolescent dataset that included both males and females.

- We address a vulnerable period with a potential for timely individual and societal interventions.

- A limitation of this study was the use of a single item question on Sl.

strongly correlates with suicidal attempt and death by suicide that remains robust even after adjusting for severity of depression and stress-events. ${ }^{4}$

In adolescents, SI is associated with an array of psychiatric disorders, most significantly mood disorders and eating disorders (EDs) ${ }^{5}$ and also anxiety, ${ }^{5}$ weight and shape concerns, ${ }^{7}$ lack of regard for one's own body, ${ }^{8}$ higher body mass index (BMI $)^{910}$ and binge/ purge symptoms. ${ }^{11} 12$ The suicide risk seems to be higher if EDs and other psychological problems coexist. ${ }^{8}$ Predictive ability of suicide risk factors has not changed much in the past 50 years, partly due to methodological problems and lack of research on a wider list of factors that can explain SI or behaviour in a way previously identified risk factors have not. ${ }^{1314}$

Studying factors associating suicide in populations with traits of ED poses certain difficulties. Since no more than one in four individuals with EDs come to the attention of clinicians, ${ }^{15}$ results derived from clinical data are less generalisable. Moreover, studies on the associations between SI and EDs have been limited to clinical data on EDs with 
primarily female participants ${ }^{16}{ }^{17}$ while for instance in Australia, one in four and in UK, one in three preadolescents who attend special ED clinics are male. ${ }^{18}{ }^{19}$ In fact, contrary to what was initially believed, prevalence of certain ED diagnoses is higher among male population than their female counterparts. ${ }^{20}{ }^{21}$ Sex differences in the clinical representation of the various specific EDs are also detected. ${ }^{17}$ Current diagnostic criteria are mainly derived from female populations and fail to identify a sizeable number of male sufferers who do not fit in the female ED profile. The importance of research in male populations with EDs cannot be emphasised more.

Another potential problem area in conducting research in populations with EDs is the heterogeneity within and across specific ED diagnoses. EDs, as classified by American Psychiatric Association, are 'Disorders of feeding and eating, ${ }^{22}$ and range from clinical forms that meet stringent diagnostic criteria of Anorexia Nervosa to forms that fluctuate in form and severity over the years and may not necessarily fall into diagnostic categories. ${ }^{22}$ In both clinical and research settings, using current diagnostic criteria will inevitably lead to missing a population who presents fewer numbers of ED symptoms that may nevertheless cause discomfort or a degree of dysfunction. This particular group is referred to as one presenting symptoms of disordered eating (DE), a clinically less pronounced form of 'disorders of feeding and eating', ${ }^{23}$ that seems to occur more frequently than EDs among adolescents, ${ }^{24-26}$ especially in those with higher BMI. ${ }^{27}$ New and large crossgender population-based research is essential in reliably understanding SI and its associated factors among adolescents with DE traits. $^{28}$

With the age for SI onset reported to be as young as 10 years,${ }^{29}$ the importance of research at young adolescence period when prevalence of both SI and eating disorders (EDs) increases ${ }^{130-32}$ cannot be overemphasised.

Accordingly, the purpose of the current investigation was to study DE traits in relation to SI in a large sample of more than 7000 Norwegian adolescents, including large numbers of male participants. Prevalence of SI, DE traits and their characteristics were studied. Having found supporting evidence in literature on adults, ${ }^{33} 34$ authors first examined whether DE or its related traits, such as weight and shape concerns, are associated with SI among adolescents and second whether such potential associations could be accounted for by other factors such as individuals' level of mental distress, BMI or socioeconomic status (SES). The authors hypothesised that SI is associated with DE and its related traits such as body size or weight perception that are independent of BMI, mental distress and SES.

\section{MATERIALS AND METHODS}

\section{Study design and population}

Research subjects participated in the Young-HUNT (YH) Study, which is the adolescent arm (13-19 years) of the Nord-Trøndelag Health Study (https://www.ntnu. edu/hunt). The HUNT Study was primarily designed to investigate major public health issues in residents of the county of Nord-Trøndelag, Norway. The YH Study comprises two cross-sectional surveys so far: YH1 (19951997) and YH3 (2006-2008). These surveys were carried out at schools (response rates between $83 \%$ and 90\%). Data on DE traits, weight and shape concerns, mental distress, SES and SI were collected through self-reported questionnaires. Clinical measurements were undertaken by specially trained nurses. The Young-HUNT database includes anonymised data on 17820 participants. Cohort profiles of both the adult HUNT Study and the YoungHUNT Study have been previously described. ${ }^{35} 36$

Data from the YH1 and YH3 were combined and used for the present analyses. Only participants 15 years of age or older were asked about SI and were therefore eligible for our study. The total of 7268 participants (4057 individuals from YH1 and 3211 from YH3) that had both questionnaire and clinical examination data were included in our study. Age and gender distribution in the YoungHUNT1 (mean age: 17.62, female: 52.1\%) and YoungHUNT3 (mean age 17.63, female: $49.0 \%$ ) were similar.

\section{Measurements}

Suicidal ideation

SI was measured by a single question asking participants: 'Have you ever had thoughts of taking your own life?' to which they could answer 'Yes' or 'No'.

\section{Disordered eating (DE)}

EAT-7, a shortened version of The EAT (Eating Attitude Test), was used to identify participants with DE (see online supplementary appendix). Individuals who were identified as having DE were then grouped into two groups: EAT-A or 'poor appetite/undereating' and EAT-B or 'uncontrolled appetite/overeating'. Association analyses were performed on sex-stratified groups with EAT-A or EAT-B compared with those without DE (reference group). For more details on EAT-7 and its psychometric properties, please see online supplementary appendix.

It is important to note that terms EDs and DE are not used interchangeably in the current study. ED has been the preferred term whenever authors referred to previous research conducted in populations with defined EDs.

\section{Body size perception}

Body size perception (BSP) was measured by asking: 'Do you consider yourself to be: 'very fat', 'quite fat', 'about the same as others', 'quite thin' or 'very thin'. Participants who perceived their body size as 'about the same as others' have been used as reference group.

\section{Intention to lose weight}

Intention to lose weight was assessed by the following question: 'Are you trying to lose weight?' to which participants could answer: (1) 'No, I am comfortable with my weight', (2) 'No, but I need to lose weight' or (3) 'Yes'. Participants who were comfortable with their weight (alternative 1) were used as reference group. 
Mental distress

The Five-item Hopkins Symptom Checklist (SCL-5), ${ }^{37}$ a valid and reliable measure of mental distress, ${ }^{38}$ was used to identify participants with a high degree of mental distress (see online supplementary appendix). Based on previously reported cut-off points, participants were grouped into those with 'high' degree of mental distress (anxiety or depression) as opposed to those with 'low' levels of mental distress who were used as reference group.

\section{Anthropometric measures}

Standardised measurements of height and weight were carried out by trained nurses where participants wore light clothing and no shoes. Weight was measured to the nearest half kilo and height to the nearest $\mathrm{cm}$. BMI was calculated as weight $(\mathrm{kg}) /$ height $^{2}\left(\mathrm{~m}^{2}\right)$. Based on standard definitions outlined by Cole and colleagues where age and gender are taken into consideration while interpreting BMI, ${ }^{39}{ }^{40}$ participants were grouped into four categories: obese, overweight, normal weight and underweight.

\section{Socioeconomic status}

Occupation, financial wealth or deprivation have previously been used as measures of SES, but education level has been reported as the best measurement to identify health inequalities. ${ }^{41}$ In our study, maternal education level is used as a proxy for SES.

Every Norwegian citizen has a unique personal 11-digit identification number, which was used to identify participants' mothers from the Norwegian Family Register. The data on education were then obtained from the Statistics Norway database (SSB) on 6852 mothers. The educational levels were coded according to the Norwegian Standard Classification of Education (NUS) into three: primary (0-10 years school attendance, reference category), secondary (11-14 years of school attendance) and tertiary (>14 years of school attendance) ${ }^{42}$

\section{Statistical analysis}

Multivariable logistic regression models were employed in sex-stratified samples to investigate the associations between DE, BSP and intention to lose weight and SI in separate models for each exposure factors. Models were adjusted for age, BMI, mental distress and SES. Results are reported as OR with 95\% CI. Overall missingness was $<5 \%$ and considered missing at random. We performed a complete case analysis. Models were fitted in IBM SPSS Statistics 25.

Based on previous reports on validity and reliability of single-item question on $\mathrm{SI}^{43}$ the authors concluded that statistical errors are less likely to have influenced the results in a meaningful way, first due to fairly large effect sizes observed and reduction in the chances for a Type II error and second due to a relatively large sample size that reduces the possibility of a Type I error. Collinearity between exposure variable was examined in linear regression model. The authors found no evidence of multicollinearity as assessed by tolerance values greater than 0.1 . Inspection of correlation coefficient showed no evidence in support of high correlations (all values were under 0.7 ).

Independent-samples t-tests and $\chi^{2}$ tests of independence (both significant at the 0.05 level) were performed to determine whether participants from YH1 and YH3 differed in ways that would affect the validity of our results derived from pooled data. Participants were compared on all exposure variables. Wherever no statistically significant differences were observed, the association analyses were done on pooled data from $\mathrm{YH} 1$ and $\mathrm{YH} 3$ cohorts. Otherwise, association analyses were done separately in $\mathrm{YH} 1$ and $\mathrm{YH} 3$ as well as on the pooled data. Comparing the results from these separate analyses detected no meaningful difference. Results are therefore reported for pooled data only.

\section{Ethics statement}

Our study was conducted in accordance to the Helsinki Declaration and was approved by the Regional and National Committees for Medical and Health Research Ethics (2009/740-2) as well as by the Norwegian Data Inspectorate. In Norway, the legal age for consent is 16 years. Written consents were obtained from participants older than 16 and from their parents or legal guardians for younger participants.

\section{Patient and public involvement statement}

Patients and the public were not involved in the design and conception of the study. Recruitment phase was entry level for the public. There are no plans to disseminate the results to patients.

\section{RESULTS}

\section{Population characteristics}

Overall prevalence of SI in our study population was 23.0\%. Prevalence of SI was similar between YH1 and YH3 (table 1). The prevalence of SI among adolescents in the poor appetite/undereating group was $44.1 \%$ and $35.0 \%$ among those in the uncontrolled appetite/overeating group, as opposed to $20.5 \%$ in participants without DE.

Uncontrolled appetite/overeating was more prevalent $(11.8 \%)$ than poor appetite/undereating $(4.7 \%)$ with girls more affected than boys in both groups (table 1 ). The prevalence of poor appetite/undereating was similar in $\mathrm{YH} 1$ and $\mathrm{YH} 3$ (4.5\% and $5.0 \%$, respectively) while the prevalence of uncontrolled appetite/overeating decreased from $\mathrm{YH} 1$ to $\mathrm{YH} 3$ (13.7\% to 9.4\%).

Compared with those without DE, more participants with DE perceived themselves as not 'about the same as others' (table 2). In the total sample, $57.2 \%$ perceived their body size as not 'about the same as others', whereas more girls compared with boys perceived themselves as 'fat' or 'very fat' while more boys, perceived themselves as 'thin' or 'very thin' (table 1). Irrespective of BMI, a general trend of underestimation of body size in boys and overestimation in girls was found (online supplementary table 1). 
Table 1 Sample characteristics $\left(n=7628^{*} ; 3659\right.$ girls, 3609 boys, mean age $=17.63$ years)

\begin{tabular}{|c|c|c|c|}
\hline & Total & Boys & Girls \\
\hline & $\mathbf{N}(\%)$ & $\mathbf{N}(\%)$ & $\mathbf{N}(\%)$ \\
\hline \multicolumn{4}{|l|}{ Suicidal ideation } \\
\hline Young-HUNT1 & $939(23.1)$ & $417(20.1)$ & $522(26.3)$ \\
\hline Young-HUNT3 & $742(23.1)$ & $311(20.2)$ & $431(25.3)$ \\
\hline \multicolumn{4}{|c|}{ Weight categories (BMI)† } \\
\hline Obese & $296(4.5)$ & $143(4.3)$ & $153(4.7)$ \\
\hline Overweight & $1072(16.4)$ & $552(16.8)$ & $520(16.1)$ \\
\hline Normal weight & $4855(74.5)$ & $2443(74.1)$ & $2412(74.8)$ \\
\hline Underweight & 296 (4.5) & $157(4.8)$ & $139(4.3)$ \\
\hline \multicolumn{4}{|l|}{ Body size perception } \\
\hline Very fat & $154(2.1)$ & $41(1.1)$ & $113(3.1)$ \\
\hline Quite fat & $1639(22.7)$ & $606(17.0)$ & $1033(28.4)$ \\
\hline $\begin{array}{l}\text { About the same as } \\
\text { others }\end{array}$ & 4119 (57.2) & $2097(58.7)$ & $2022(55.7)$ \\
\hline Quite thin & $1210(16.8)$ & $771(21.4)$ & $439(12.1)$ \\
\hline Very thin & $84(1.2)$ & $58(1.6)$ & $26(0.7)$ \\
\hline \multicolumn{4}{|l|}{ Intention to lose weight } \\
\hline Yes & $1085(15.1)$ & $256(7.2)$ & 829 (22.9) \\
\hline $\begin{array}{l}\text { No, but I need to } \\
\text { lose weight }\end{array}$ & $1282(17.8)$ & $428(12.0)$ & $854(23.6)$ \\
\hline $\begin{array}{l}\text { No, I am } \\
\text { comfortable with } \\
\text { my weight }\end{array}$ & $4827(67.1)$ & $2890(80.9)$ & $1937(53.5)$ \\
\hline \multicolumn{4}{|l|}{ Disordered eating } \\
\hline $\begin{array}{l}\text { Poor appetite/ } \\
\text { undereating }\end{array}$ & $338(4.7)$ & $74(2.1)$ & $264(7.3)$ \\
\hline $\begin{array}{l}\text { Uncontrolled } \\
\text { appetite/overeating }\end{array}$ & $843(11.8)$ & $363(10.2)$ & $480(13.3)$ \\
\hline Anxiety/depression & 1484 (20.9) & $439(12.5)$ & 1045 (29.2) \\
\hline
\end{tabular}

*Subgroups may not sum to total number due to missing values. †Weight categories are calculated according to Cole et al (2000) ${ }^{39}$ (2000) and Cole et al (2007)..$^{40}$

Majority of participants (67.1\%) were comfortable with their weight (table 1). Compared with boys and irrespective of their actual BMI, more girls were unhappy with their weight (online supplementary table 2). Such gender differences became even more pronounced in participants with DE (table 2).

Girls and boys differed very little in terms of BMI distribution in the total sample (table 1). Compared with the YH1 sample, BMI distribution shifted towards obese and overweight in YH3, with a greater shift towards obese and overweight in boys (online supplementary table 1).

Overall, $20.9 \%$ of the participants reported having higher levels of mental distress as defined by SCL-5 (table 1). Independent of presence or absence of $\mathrm{DE}$, girls showed significantly higher prevalence of mental distress than the boys (data not shown).

\section{Association between suicidal ideation and disordered eating}

Compared with those without DE and in both genders, the odds for SI were more than doubled in the poor appetite/undereating group and almost doubled in the uncontrolled appetite/overeating group. Adjustment for age made negligible changes in the OR for SI; however, adjustments for BMI further increased the odds in both sexes without losing statistical significance (tables 3 and 4). With further adjustments for mental distress, the odds for SI remained statistically significant in both sexes in the respective DE subgroups although the effect sizes decreased. After adjustment made for age, BMI and mental distress, boys had higher odds for SI compared with girls in both DE groups (tables 3 and 4).

\section{Association between suicidal ideation and body size perception}

In both sexes, perceiving body size as not 'about the same as others' ('very fat', 'quite fat', 'quite thin' or 'very thin') was associated with higher odds for SI. For instance, boys who perceived their body size as 'very fat' showed an OR of 4.45 (2.38-8.31) compared with boys who perceived their body size as 'about the same as others'. The same comparison in girls yielded an OR for SI of 5.54 (3.758.18). Similar observations were made in boys or girls who perceived their body size as 'quite fat'. Higher odds for SI in groups with BSP as 'quite thin' or 'very thin' were only statistically significant in boys (see tables 3 and 4 ). All results were robust to adjustment for age, BMI and SCL-5. In both sexes, ORs for SI were higher the farther BSP deviated from the population norm ('about the same as others'), in either direction. With some small exceptions, adjustment for mental distress reduced the odds for SI across all BSP groups in both girls and boys (tables 3 and 4). Compared with boys, girls who considered their body size as 'very fat' showed slightly higher odds of SI after adjustments for age and BMI. Potential moderator effect of sex was examined in a two-way analysis of covariance model in the full dataset with interaction terms. We found no statistical evidence that sex had significant moderator effect on the association between BSP 'very fat' and SI ( $p$ value: 0.118 ).

\section{Association between suicidal ideation and intention to lose weight}

In the crude analyses, 'intention to lose weight', even without actively engaging in weight reduction measures, more than doubled the odds for SI in both genders (tables 3 and 4). Compared with those who 'did not try to lose weight', the OR for SI in those who intended to lose weight was doubled in boys and nearly tripled in girls. These findings were robust to adjustments made for age, BMI and mental distress (tables 3 and 4).

\section{Testing for possible confounding effect of socioeconomic status (SES)}

A subsample of 6852 participants with available information on highest maternal education level was used 
Table 2 Intention to lose weight and body size perception in individuals with DE in pooled data

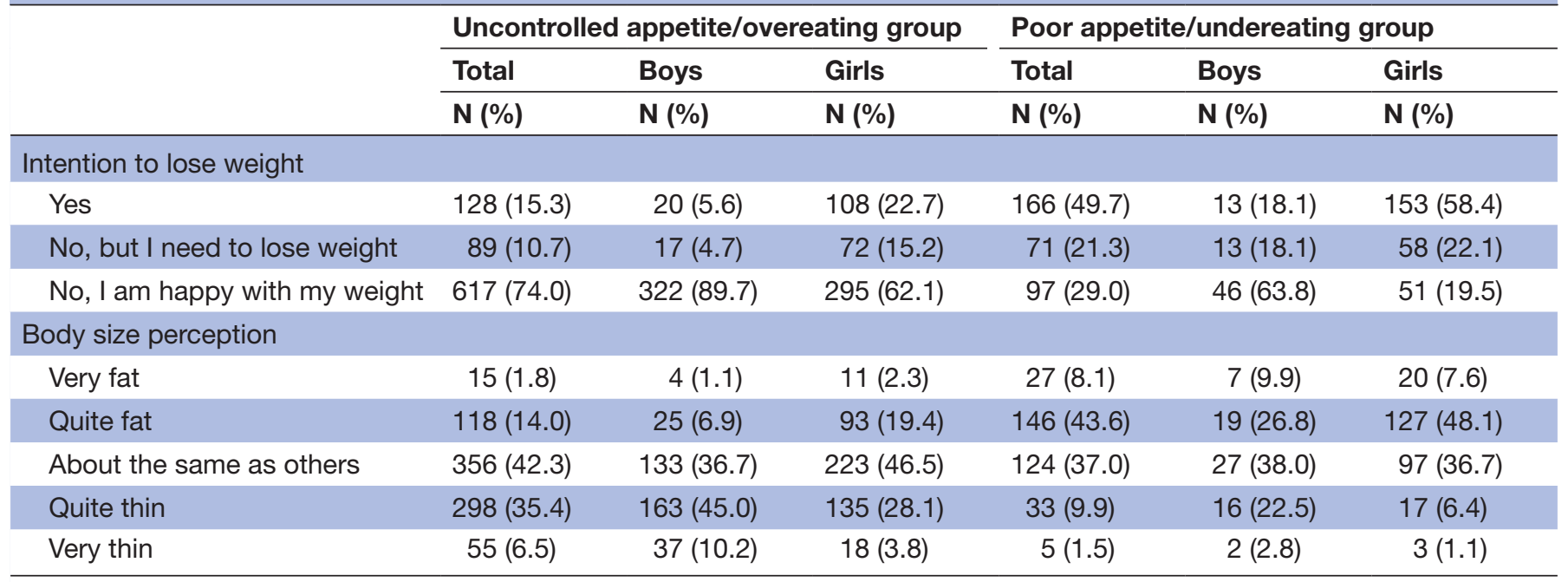

$\mathrm{DE}$, disordered eating.

to investigate possible confounding effect of SES on the associations between SI and DE, BSP or intention to lose weight. Adjusting for SES made very slight change to our findings (tables 3 and 4).

\section{DISCUSSION}

\section{Principal findings of this study}

Our findings point at a considerable collective increase in the odds for SI among adolescents with traits of DE, body size or weight concerns as well as with other factors such as BMI and mental distress. Adolescent boys with
DE traits showed a vulnerability for having SI and require special attention in suicide risk assessment and treatment approaches.

\section{Comparison with previous studies}

In line with previous reports, ${ }^{27}$ we found that $\mathrm{DE}$ was far more prevalent than clinically diagnosed EDs, suggesting that in identification of vulnerable individuals and groups, more weight should be given to the presence of DE symptoms and traits rather than solely to presence or absence of a clinical diagnoses (EDs). A sizeable proportion of

Table 3 ORs for SI given disordered eating, body size perception or intention to lose weight in boys

\begin{tabular}{|c|c|c|c|c|c|c|c|c|c|c|}
\hline & \multicolumn{2}{|c|}{ Non-adjusted } & \multicolumn{2}{|c|}{ Adj. for age } & \multicolumn{2}{|c|}{ Adj. for age/BMI } & \multicolumn{2}{|c|}{$\begin{array}{l}\text { Adj. for age/BMI/ } \\
\text { SCL-5 }\end{array}$} & \multicolumn{2}{|c|}{$\begin{array}{l}\text { Adj. for age/BMI/ } \\
\text { SCL-5/SES }\end{array}$} \\
\hline & OR & $95 \% \mathrm{Cl}$ & OR & $95 \% \mathrm{Cl}$ & OR & $95 \% \mathrm{Cl}$ & OR & $95 \% \mathrm{Cl}$ & OR & $95 \% \mathrm{Cl}$ \\
\hline $\begin{array}{l}\text { Poor appetite/ } \\
\text { Undereating }\end{array}$ & $2.47^{\star}$ & 1.53 to 3.98 & $2.47^{\star}$ & 1.53 to 3.97 & $2.87^{\star}$ & 1.75 to 4.71 & $2.10^{\star *}$ & 1.19 to 3.73 & $2.28^{\star *}$ & 1.26 to 4.11 \\
\hline $\begin{array}{l}\text { Uncontrolled } \\
\text { appetite/Overeating }\end{array}$ & $1.95^{\star}$ & 1.53 to 2.47 & $1.95^{\star}$ & 1.53 to 2.47 & $2.09^{*}$ & 1.61 to 2.71 & $1.77^{*}$ & 1.34 to 2.35 & $1.81^{\star}$ & 1.35 to 2.42 \\
\hline \multicolumn{11}{|l|}{ Body size perception } \\
\hline Very fat & $4.45^{\star}$ & 2.38 to 8.31 & $4.44^{*}$ & 2.38 to 8.30 & $5.68^{*}$ & 2.78 to 11.61 & $4.20^{\star}$ & 1.96 to 9.02 & $4.43^{*}$ & 2.02 to 9.71 \\
\hline Quite fat & $1.93^{*}$ & 1.56 to 2.39 & $1.93^{*}$ & 1.56 to 2.39 & $2.13^{*}$ & 1.63 to 2.78 & $1.74^{\star}$ & 1.31 to 2.32 & $1.64^{\star *}$ & 1.22 to 2.21 \\
\hline Quite thin & $1.44^{\star *}$ & 1.17 to 1.76 & $1.44^{\star \star}$ & 1.17 to 1.76 & $1.53^{*}$ & 1.22 to 1.92 & $1.47^{\star *}$ & 1.16 to 1.87 & $1.51^{\star *}$ & 1.18 to 1.93 \\
\hline Very thin & $3.15^{\star}$ & 1.83 to 5.42 & $3.14^{*}$ & 1.83 to 5.41 & $3.82^{\star}$ & 2.06 to 7.08 & $3.39^{\star}$ & 1.75 to 6.53 & $2.99^{\star \star}$ & 1.51 to 5.92 \\
\hline \multicolumn{11}{|l|}{ Intention to lose weight } \\
\hline
\end{tabular}

Reference category in the dependent variable: no SI. Reference categories in the predictors: Disordered eating: below cut-off for each trait. Body size perception: about the same as others. Intention to lose weight: No. Adjustment for SES from a subsample of 6852 participants. Primary level education used as reference category. ${ }^{*} \mathrm{P}<0.001,{ }^{* *} \mathrm{p}<0.05$.

BMI, body mass index; SCL-5, The Five-item Hopkins Symptom Checklist; SES, socioeconomic status; SI, suicidal ideation. 
Table 4 ORs for SI given disordered eating, body size perception or intention to lose weight in girls

\begin{tabular}{|c|c|c|c|c|c|c|c|c|c|c|}
\hline & \multicolumn{2}{|c|}{ Non-adjusted } & \multicolumn{2}{|c|}{ Adj. for age } & \multicolumn{2}{|c|}{ Adj. for age/BMI } & \multicolumn{2}{|c|}{$\begin{array}{l}\text { Adj. for age/BMI/ } \\
\text { SCL-5 }\end{array}$} & \multicolumn{2}{|c|}{$\begin{array}{l}\text { Adj. for age/BMI/ } \\
\text { SCL-5/SES }\end{array}$} \\
\hline & OR & $95 \% \mathrm{Cl}$ & OR & $95 \% \mathrm{Cl}$ & OR & $95 \% \mathrm{Cl}$ & OR & $95 \% \mathrm{Cl}$ & OR & $95 \% \mathrm{Cl}$ \\
\hline \multicolumn{11}{|l|}{ Disordered eating } \\
\hline $\begin{array}{l}\text { Poor appetite/ } \\
\text { Undereating }\end{array}$ & $2.62^{*}$ & 2.03 to 3.38 & $2.63^{\star}$ & 2.04 to 3.39 & $2.83^{\star}$ & 2.17 to 3.70 & $1.78^{\star}$ & 1.33 to 2.39 & $1.75^{\star}$ & 1.30 to 2.37 \\
\hline $\begin{array}{l}\text { Uncontrolled appetite/ } \\
\text { Overeating }\end{array}$ & $1.94^{\star}$ & 1.58 to 2.37 & $1.93^{*}$ & 1.58 to 2.37 & $2.05^{\star}$ & 1.65 to 2.55 & $1.56^{\star}$ & 1.23 to 1.98 & $1.58^{*}$ & 1.23 to 2.02 \\
\hline Very fat & $5.54^{*}$ & 3.75 to 8.18 & $5.48^{*}$ & 3.71 to 8.09 & $5.88^{*}$ & 3.67 to 9.45 & $3.96^{*}$ & 2.34 to 6.69 & $4.04^{*}$ & 2.35 to 6.92 \\
\hline Quite fat & $2.09^{*}$ & 1.77 to 2.47 & $2.10^{\star}$ & 1.77 to 2.48 & $2.24^{*}$ & 1.84 to 2.73 & $1.82^{\star}$ & 1.47 to 2.26 & $1.85^{\star}$ & 1.49 to 2.30 \\
\hline Quite thin & 1.26 & 0.98 to 1.60 & 1.25 & 0.98 to 1.60 & 1.25 & 0.95 to 1.64 & 1.34 & 0.10 to 1.79 & 1.35 & 1.00 to 1.82 \\
\hline Very thin & 2.09 & 0.92 to 4.72 & 2.04 & 0.9 to 4.61 & $2.53^{\star \star}$ & 1.07 to 6.01 & $2.8^{\star \star}$ & 1.13 to 6.94 & 2.45 & 0.95 to 6.30 \\
\hline
\end{tabular}

Reference category in the dependent variable: no SI. Reference categories in the predictors: Disordered eating: below cut-off for each trait. Body size perception: about the same as others (normal). Intention to lose weight: no. Adjustment for SES from a subsample of 6852 participants. Primary level education used as reference category. ${ }^{*} \mathrm{P}<0.001,{ }^{*} \mathrm{p}<0.05$.

BMI, body mass index; SCL-5, The Five-item Hopkins Symptom Checklist; SES, socioeconomic status; SI, suicidal ideation.

high-risk individuals do not meet stringent diagnostic criteria for EDs and hence might slip through the safety net before a suitable care approach can be warranted.

There is a high comorbidity between DE and mental distress in the form of anxiety or depressive disorders, ${ }^{44}$ both closely linked to SI and attempted suicide. ${ }^{6} \mathrm{DE}$ or subjective perception of body shape or weight is not routinely included in clinical suicide risk assessments which might lead to underestimation of vulnerability to future SI or suicidal attempts.

Although our findings were of similar calibre and direction in both sexes, we observed some sex differences concerning BMI and mental distress. Our observations were in line with previously found sex differences in 1clinical manifestations of $\mathrm{EDs}^{45}$ or 2- BSP in relation to actual BMI, ${ }^{46}{ }^{47}$ with girls showing a tendency to overestimate and boys consistently underestimating their body size. In keeping with previous reports, ${ }^{45} 4849$ our male participants showed less inclination than the females to lose weight, independent of their actual BMI. Unlike previous research that has accounted BMI for gender differences in ED manifestations, ${ }^{50}{ }^{51}$ higher BMI could not explain higher OR for SI among our male participants with DE traits, possibly because they were not as much concerned with their BMI as they are with looking masculine and lean.$^{52}$ In contrast, their female counterparts seem to be more concerned about their weight, ${ }^{53}$ which in effect renders BMI less indicative of presence or severity of DE among males. Similar to previous reports, ${ }^{54}$ we found higher vulnerability to mental distress among adult male sufferers of DE. This higher vulnerability is possibly a reflection of higher prevalence of a wider array of comorbid psychiatric disorders ${ }^{17}$ among these male sufferers of DE. Presence of psychiatric comorbidities can potentiate existing associations between DE and SI among males with DE. Furthermore, male populations seem to be more reluctant in seeking help for their symptoms ${ }^{17}$ which can further exacerbate the associations between DE and SI as these individuals will not be receiving help for either condition. Further research is required for understanding what constitutes this gender difference. Considering the increase in the incidence rates of EDs among men who also seem to present different set of symptoms of EDs, screening and treating men with EDs is becoming more and more a priority ${ }^{55}$ Current reliance on a diagnostic framework based on thinness ${ }^{17}$ fails in identification of muscularity-oriented pathology of EDs in male population, in clinical or research settings.

Some discrepancy between participants' actual BMI and BSP was observed (see online supplementary table 1) where individuals inaccurately perceived their own body size by means of underestimation or overestimation. The direction of BSP inaccuracy, as underestimation or overestimation of BSP, in conjunction with gender specific societal body ideals might have some real implications in the degree with which BSP inaccuracy might further associate with mental distress and SI. But one can argue that inaccurate BSP might not necessarily lead to higher mental distress, for instance, if the direction of BSP inaccuracy qualifies individuals to a more favourable position in relation to what society regards as normal or ideal. BSP inaccuracy by underestimation might cause less mental distress in female individuals who are obese or overweight but perceive their body size as normal or underweight, in effect rebranding own's BSP in a more approved fashion (following agreed societal norms). Possible associations 
between BSP, BSP accuracy, BMI and intention to lose weight require full exploration that is beyond the scope of current study but is being investigated in a parallel study conducted (by the authors) on determinants of dieting in a Norwegian community sample (the HUNT Study).

\section{Strengths and limitations}

Strengths of this study include the large sample size derived from a total Norwegian adolescent population with a homogenous ethnic background. Further, anthropometric measurements were carried out by trained nurses. To date, most studies on EDs have relied on clinical data or patient registries of adult population ${ }^{56}$ which leaves out the adolescents in the general population in the time period when psychological distress and disorders often manifest. With the median age of onset for developing EDs reported as low as $12-13$ years old,${ }^{57}$ the importance of studying younger affected individuals could not be more emphasised. Studies on male ED sufferers are fewer and far in between, with adolescent male participants usually lumped into adult populations. ${ }^{45}$ Our results are of general relevance since our observations were made in a large, population-based adolescent dataset that included both males and females.

Conclusions should be drawn in the light of certain limitations in the current study. The use of shortened and self-reported measures of DE (EAT-7) or mental distress (SCL-5), and not standardised psychiatric interviews, has in effect rendered our findings less generalisable to clinical populations. SI was assessed by a single item question. Due to temporal bias in a cross-sectional design, we are not able to assess potential causal relationships between DE traits and SI. We do not interpret our results as causal but rather associative, hence, the importance of conducting future longitudinal studies on causality in larger populations. One interesting line of enquiry is to look at various DE traits clustered in smaller groups based on participants' BMI or BSP, which was not possible to perform in the current study given small number of participants in each cluster. Conducting a follow-up study on a larger dataset from the HUNT Study including adolescents from the most recent data collection, HUNT4 Survey (2017-2019), may reach a higher statistical power and hence more conclusive results. Using single-item question on SI in future studies provides an opportunity of validation and to confirm the results obtained here and is hence encouraged by the authors; however, to overcome miscalculation or misinterpretation errors, adding follow-up questions will supplement information derived from a single-item question on SI. Time lapse since YH1 makes prevalence reports from that time less reflective of the current situation; however, authors found no evidence that suggested pooling data from $\mathrm{YH} 1$ and YH3 would render the study findings less valid. On the other hand, older cohorts such as $\mathrm{YH} 1$ are useful in retrospective research on potential time trends in DE manifestations or their potential impact on prevalence of SI among adolescence. Furthermore, such retrospective studies can provide inferential insight into, for example, how environmental changes might have associated with time trends of DE traits among adolescents.

\section{CONCLUSION}

An individually tailored approach to suicide risk assessment and management seems to be more appropriate in subpopulations of adolescents with DE and its related traits. Our findings on difference between female and male adolescents may have potential implications in the way clinicians address SI across genders. Shifting focus from maintaining a healthy BMI to addressing individuals' attitudes towards their own body shape and size is important in designing treatment plans that reduce burden of SI or attempts. Timely identification of associated factors for SI in high-risk but non-clinical populations is important in designing strategic and preventive measures that intend to cut human and economic costs of SI and attempts. Future longitudinal research in both clinical and community populations, preferably with data on onset, frequency and severity of SI in comparison to that of DE traits could help in overcoming current methodological and interpretational difficulties in drawing more conclusive results on temporal relationship between these factors.

\section{Author affiliations}

${ }^{1}$ Institute for Public Health, Medical Faculty, Norwegian University of Science and Technology NTNU, Trondheim, Trøndelag, Norway

${ }^{2}$ Brøset Department, Regional Higher Security Psychiatry Department, Trondheim, Trøndelag, Norway

${ }^{3}$ HUNT Research Center, Department of Public Health and General Practice, Norwegian University of Science and Technology, Levanger, Nord-Trøndelag, Norway ${ }^{4}$ Child and Adolescent Psychiatry, Faculty of Medicine, Universite de Geneve, Geneva, Switzerland

${ }^{5}$ Behavioral and Brain Science Unit, University College London, London, UK ${ }^{6}$ Department of Public Health and General Practice, Faculty of Medicine, Norwegian University of Science and Technology, Levanger, Norway

${ }^{7}$ Faculty of Nursing and Health Sciences, Nord University, Levanger, Norway ${ }^{8}$ Department of Mental Health, Faculty of Medicine and Health Sciences, Norges teknisk-naturvitenskapelige universitet, Trondheim, Norway

${ }^{9}$ Department of Public Health and General Practice, Medical Faculty, Norges Teknisk Naturvitenskapelige Universitet Institutt for Samfunnsmedisin, Trondheim, Norway ${ }^{10}$ Centre for Sami Health Research, Department of Community Medicine, UiT The Arctic University of Norway, Tromsø, Norway

Acknowledgements The material described in this paper is original research and has not been previously published or submitted for publication elsewhere.

Contributors FSS has conceived the idea, performed the analyses and drafted the manuscript. FSS, TLH, NM, ERS, OB and KK have contributed to interpretation of results and critical revision of manuscript. FSS, TLH, NM, ERS, OB and KK have read and approved of the final version of manuscript before its submission. FSS, TLH, NM, ERS, OB and KK can be held accountable for all aspects of the work.

Funding The Nord-Trøndelag Health Study (the HUNT Study) is collaboration between HUNT Research Center (Faculty of Medicine, Norwegian University of Science and Technology NTNU), Nord-Trøndelag County Council, Central Norway Health Authority and Norwegian Institute of Public Health. This study was funded through a PhD scholarship by medical faculty, NTNU awarded to FSS for her doctoral study.

Competing interests None declared.

Patient consent for publication Not required. 
Provenance and peer review Not commissioned; externally peer reviewed.

Data sharing statement Due to restrictions imposed by the HUNT Research Centre (in accordance with Norwegian Data Inspectorate), data cannot be made publicly available. Data are currently stored in the HUNT databank, and there are restrictions in place for the handling of HUNT data files. Data used from the HUNT Study in research projects will be made available on request to the HUNT Data Access Committee (hunt@medicine.ntnu.no).The HUNT data access information (available here: http://www.ntnu.edu/hunt/data) describes in detail the policy regarding data availability.

Open access This is an open access article distributed in accordance with the Creative Commons Attribution Non Commercial (CC BY-NC 4.0) license, which permits others to distribute, remix, adapt, build upon this work non-commercially, and license their derivative works on different terms, provided the original work is properly cited, appropriate credit is given, any changes made indicated, and the use is non-commercial. See: http://creativecommons.org/licenses/by-nc/4.0/.

\section{REFERENCES}

1. Nock MK, Green JG, Hwang I, et al. Prevalence, correlates, and treatment of lifetime suicidal behavior among adolescents: results from the National Comorbidity Survey Replication Adolescent Supplement. JAMA Psychiatry 2013;70:300-10.

2. WHO. Preventing suicide: A global imperative. 2014

3. Trout ZM, Hernandez EM, Kleiman EM, et al. Prospective prediction of first lifetime suicide attempts in a multi-site study of substance users. J Psychiatr Res 2017;84:35-40.

4. Park EH, Hong N, Jon DI, et al. Past suicidal ideation as an independent risk factor for suicide behaviours in patients with depression. Int J Psychiatry Clin Pract 2017;21:24-8.

5. Franko DL, Keel PK. Suicidality in eating disorders: occurrence, correlates, and clinical implications. Clin Psychol Rev 2006;26:769-82.

6. Milos G, Spindler A, Hepp U, et al. Suicide attempts and suicidal ideation: links with psychiatric comorbidity in eating disorder subjects. Gen Hosp Psychiatry 2004;26:129-35.

7. Ackard DM, Fulkerson JA, Neumark-Sztainer D. Psychological and behavioral risk profiles as they relate to eating disorder diagnoses and symptomatology among a school-based sample of youth. Int J Eat Disord 2011;44:440-6.

8. Smith AR, Ortiz SN, Forrest LN, et al. Which Comes First? An Examination of Associations and Shared Risk Factors for Eating Disorders and Suicidality. Curr Psychiatry Rep 2018;20:77.

9. Dreber H, Reynisdottir S, Angelin B, et al. Mental distress in treatment seeking young adults (18-25 years) with severe obesity compared with population controls of different body mass index levels: cohort study. Clin Obes 2017;7:1-10.

10. Minor T, Ali MM, Rizzo JA. Body Weight and Suicidal Behavior in Adolescent Females: The Role of Self-Perceptions. J Ment Health Policy Econ 2016;19:21-31.

11. Pisetsky EM, Thornton LM, Lichtenstein $P$, et al. Suicide attempts in women with eating disorders. J Abnorm Psychol 2013;122:1042-56.

12. Portzky G, van Heeringen K, Vervaet $M$. Attempted suicide in patients with eating disorders. Crisis 2014;35:378-87.

13. Franklin JC, Ribeiro JD, Fox KR, et al. Risk factors for suicida thoughts and behaviors: A meta-analysis of 50 years of research. Psychol Bull 2017;143:187-232.

14. Ribeiro JD, Franklin JC, Fox KR, et al. Self-injurious thoughts and behaviors as risk factors for future suicide ideation, attempts, and death: a meta-analysis of longitudinal studies. Psychol Med 2016;46:225-36.

15. Hart LM, Granillo MT, Jorm AF, et al. Unmet need for treatment in the eating disorders: a systematic review of eating disorder specific treatment seeking among community cases. Clin Psychol Rev 2011;31:727-35

16. Sweeting $\mathrm{H}$, Walker L, MacLean A, et al. Prevalence of eating disorders in males: a review of rates reported in academic research and UK mass media. Int J Mens Health 2015;14.

17. Murray SB, Nagata JM, Griffiths S, et al. The enigma of male eating disorders: A critical review and synthesis. Clin Psychol Rev 2017;57:1-11.

18. Madden S, Morris A, Zurynski YA, et al. Burden of eating disorders in 5-13-year-old children in Australia. Med J Aust 2009;190:410-4.

19. Nicholls DE, Lynn R, Viner RM. Childhood eating disorders: British national surveillance study. Br J Psychiatry 2011;198:295-301.

20. Bryant-Waugh R. Feeding and eating disorders in children. Curr Opin Psychiatry 2013;26:537-42.
21. Eddy KT, Thomas JJ, Hastings E, et al. Prevalence of DSM5 avoidant/restrictive food intake disorder in a pediatric gastroenterology healthcare network. Int J Eat Disord 2015;48:464-70.

22. Arlington V. Feed \& eating disorders in Diagnostic and statistical manual of mental disorders. 5th ed: American Psychiatric Association, 2013.

23. Lewinsohn PM, Striegel-Moore RH, Seeley JR. Epidemiology and natural course of eating disorders in young women from adolescence to young adulthood. J Am Acad Child Adolesc Psychiatry 2000;39:1284-92.

24. Glazer KB, Sonneville KR, Micali N, et al. The Course of Eating Disorders Involving Bingeing and Purging Among Adolescent Girls: Prevalence, Stability, and Transitions. J Adolesc Health 2019;64:165-71.

25. Stice E, Marti CN, Rohde P. Prevalence, incidence, impairment, and course of the proposed DSM-5 eating disorder diagnoses in an 8 -year prospective community study of young women. J Abnorm Psychol 2013;122:445-57.

26. Allen KL, Byrne SM, Oddy WH, et al. DSM-IV-TR and DSM-5 eating disorders in adolescents: prevalence, stability, and psychosocial correlates in a population-based sample of male and female adolescents. J Abnorm Psychol 2013;122:720-32.

27. Micali N, Hagberg KW, Petersen I, et al. The incidence of eating disorders in the UK in 2000-2009: findings from the General Practice Research Database. BMJ Open 2013;3:e002646.

28. Allen KL. Understanding Eating Disorders Across Samples and Stages. J Adolesc Health 2019;64:143-4.

29. Borges G, Benjet C, Medina-Mora ME, et al. Suicide ideation, plan, and attempt in the Mexican adolescent mental health survey, J Am Acad Child Adolesc Psychiatry 2008;47:41-52.

30. Micali N, Solmi F, Horton NJ, et al. Adolescent Eating Disorders Predict Psychiatric, High-Risk Behaviors and Weight Outcomes in Young Adulthood. J Am Acad Child Adolesc Psychiatry 2015;54:652-9.

31. Evans E, Hawton K, Rodham K, et al. The prevalence of suicidal phenomena in adolescents: a systematic review of population-based studies. Suicide Life Threat Behav 2005;35:239-50.

32. Strandheim A, Bjerkeset $O$, Gunnell D, et al. Risk factors for suicidal thoughts in adolescence--a prospective cohort study: the YoungHUNT study. BMJ Open 2014;4:e005867.

33. Goel NJ, Sadeh-Sharvit S, Flatt RE, et al. Correlates of suicidal ideation in college women with eating disorders. Int J Eat Disord 2018;51:579-84.

34. Eichen DM, Kass AE, Fitzsimmons-Craft EE, et al. Non-suicidal self-injury and suicidal ideation in relation to eating and general psychopathology among college-age women. Psychiatry Res 2016;235:77-82.

35. Holmen TL, Bratberg G, Krokstad S, et al. Cohort profile of the Young-HUNT Study, Norway: a population-based study of adolescents. Int J Epidemiol 2014;43:536-44.

36. Krokstad S, Langhammer A, Hveem K, et al. Cohort Profile: the HUNT Study, Norway. Int J Epidemiol 2013;42:968-77.

37. Strand $\mathrm{BH}$, Dalgard OS, Tambs K, et al. Measuring the mental health status of the Norwegian population: a comparison of the instruments SCL-25, SCL-10, SCL-5 and MHI-5 (SF-36). Nord J Psychiatry 2003;57:113-8.

38. Tambs K, Moum T. How well can a few questionnaire items indicate anxiety and depression? Acta Psychiatr Scand 1993;87:364-7.

39. Cole TJ, Bellizzi MC, Flegal KM, et al. Establishing a standard definition for child overweight and obesity worldwide: international survey. BMJ 2000;320:1240-3.

40. Cole TJ, Flegal KM, Nicholls D, et al. Body mass index cut offs to define thinness in children and adolescents: international survey. BMJ 2007;335:194.

41. Shavers VL. Measurement of socioeconomic status in health disparities research. J Natl Med Assoc 2007;99:1013-23.

42. SSB. Norwegian standard classification of education (Norsk standard for utdanningsgruppering), Rev. 2000 eth ed. Statistics Norway(SSB) 2003:C617.

43. Millner AJ, Lee MD, Nock MK. Single-Item Measurement of Suicidal Behaviors: Validity and Consequences of Misclassification. PLoS One 2015;10:e0141606.

44. O'Brien KM, Vincent NK. Psychiatric comorbidity in anorexia and bulimia nervosa: nature, prevalence, and causal relationships. Clin Psychol Rev 2003;23:57-74.

45. Andersen AE, Holman JE. Males with eating disorders: challenges for treatment and research. Psychopharmacol Bull 1997;33:391-7.

46. Buscemi S, Marventano S, Castellano S, et al. Role of anthropometric factors, self-perception, and diet on weight 
misperception among young adolescents: a cross-sectional study. Eat Weight Disord 2018;23.

47. Fan M, Jin Y, Khubchandani J. Overweight Misperception among Adolescents in the United States. J Pediatr Nurs 2014;29:536-46.

48. Rodgers RF, Peterson KE, Hunt AT, et al. Racial/ethnic and weight status disparities in dieting and disordered weight control behaviors among early adolescents. Eat Behav 2017;26:104-7.

49. Carlat DJ, Camargo CA. Review of bulimia nervosa in males. Am J Psychiatry 1991;148:831-43.

50. Crisp AH, Burns T, Bhat AV. Primary anorexia nervosa in the male and female: a comparison of clinical features and prognosis. $\mathrm{Br} \mathrm{J}$ Med Psychol 1986;59(Pt 2):123-32.

51. Gueguen J, Godart N, Chambry J, et al. Severe anorexia nervosa in men: comparison with severe AN in women and analysis of mortality. Int J Eat Disord 2012;45:537-45.

52. Murray SB, Griffiths S, Mond JM. Evolving eating disorder psychopathology: conceptualising muscularity-oriented disordered eating. Br J Psychiatry 2016;208:414-5.
53. Strober M, Freeman R, Lampert C, et al. Are there gender differences in core symptoms, temperament, and short-term prospective outcome in anorexia nervosa? Int $J$ Eat Disord 2006;39:570-5.

54. Striegel-Moore RH, Garvin V, Dohm FA, et al. Psychiatric comorbidity of eating disorders in men: a national study of hospitalized veterans. Int J Eat Disord 1999;25:399-404.

55. Strother E, Lemberg R, Stanford SC, et al. Eating disorders in men: underdiagnosed, undertreated, and misunderstood. Eat Disord 2012;20:346-55.

56. Solmi F, Hatch SL, Hotopf M, et al. Prevalence and correlates of disordered eating in a general population sample: the South East London Community Health (SELCoH) study. Soc Psychiatry Psychiatr Epidemiol 2014;49:1335-46.

57. Swanson SA, Crow SJ, Le Grange D, et al. Prevalence and correlates of eating disorders in adolescents. Results from the national comorbidity survey replication adolescent supplement. Arch Gen Psychiatry 2011;68:714-23. 